Tropical Journal of Pharmaceutical Research December 2017; 16 (12): 2895-2901

ISSN: 1596-5996 (print); 1596-9827 (electronic) (1) Pharmacotherapy Group, Faculty of Pharmacy, University of Benin, Benin City, 300001 Nigeria.

Available online at http://www.tjpr.org Original Research Article

http://dx.doi.org/10.4314/tjpr.v16i12.13

\title{
Thymol inhibits cell migration and invasion by downregulating the activation of PI3K/AKT and ERK pathways in human colon cancer cells
}

\author{
Ran Lv', Zhenzhou Chen ${ }^{2 *}$ \\ ${ }^{1}$ Gastroenterology Department of Chinese Medicine, China-Japan Friendship Hospital, Beijing 100029, ${ }^{2}$ General Surgery \\ Department, Dongzhimen Hospital of Beijing University of Chinese Medicine, Beijing 100700, China
}

*For correspondence: Email: chenzhenzhou6@gmail.com; Tel: +86-10-84013135

\begin{abstract}
Purpose: To assess the anti-metastasis effects of thymol on human colorectal cancer cells. Methods: Human colorectal adenocarcinoma cell HT29 was incubated with varying concentrations of thymol. Cell viability, migration and invasion were determined by 3-(4, 5-dimethylthiazol-2-yl)-2, 5dipheny-tetrazoliumbromide (MTT) and Transwell assays, respectively. Matrix metalloproteinase-2 and 9 (MMP-2 and MMP-9) were analyzed by gel zymogram assay. Epithelial-mesenchymal transition (EMT)-associated gene expression and signaling pathway were analyzed using real-time quantitative polymerase chain reaction (PCR) and Western blotting, respectively.

Results: Thymol was significantly inhibited migration and invasion of HT29 cell $(p<0.01)$ and also markedly reduced the activity of matrix degrading enzymes MMP-2 and MMP-9 $(p<0.01)$. Moreover, the epithelial marker, E-cadherin, was elevated, while mesenchymal markers (vimentin and $\alpha$-SMA), and associated transcription factors (snail and slug) decreased after thymol treatment $(p<0.01)$. In addition, thymol inhibited the phosphorylation of PI3K/AKT and ERK pathways $(p<0.01)$.

Conclusion: Thymol efficiently attenuates cell migration and invasion by decreasing EMT and downregulating the activation of PI3K/AKT and ERK signaling pathways in colorectal adenocarcinoma cells. It is, thus, a potential candidate drug for the management of colorectal cancer.
\end{abstract}

Keywords: Thymol, Colorectal cancer, Anti-metastasis, Epithelial-mesenchymal transition, Vimentin, $P I 3 K / A K T$ and ERK pathway

\footnotetext{
This is an Open Access article that uses a funding model which does not charge readers or their institutions for access and distributed under the terms of the Creative Commons Attribution License (http://creativecommons.org/licenses/by/4.0) and the Budapest Open Access Initiative (http://www.budapestopenaccessinitiative.org/read), which permit unrestricted use, distribution, and reproduction in any medium, provided the original work is properly credited.
}

Tropical Journal of Pharmaceutical Research is indexed by Science Citation Index (SciSearch), Scopus, International Pharmaceutical Abstract, Chemical Abstracts, Embase, Index Copernicus, EBSCO, African Index Medicus, JournalSeek, Journal Citation Reports/Science Edition, Directory of Open Access Journals (DOAJ), African Journal Online, Bioline International, Open-J-Gate and Pharmacy Abstracts

\section{INTRODUCTION}

Colorectal cancer (CRC), one kind of the most digestive tract tumors, is the most common reason of cancer-related death, with between one and two million new cases diagnosed every year, and its incidence has been increasing year by year [1]. Modifiable risk factors for CRC related to lifestyle including smoking, physical activity habits, overweight, obesity and alcohol consumption. Chemotherapy and surgery are the most common treatment for CRC. CRC treatment has improved due to the application of a new generation of chemotherapy and 
molecular-targeted drugs, but it remains unsatisfactory. Moreover, the toxic side effects of chemotherapy drugs and the failure of chemotherapeutic due to drug resistance are some of the drawbacks of clinical treatment [2]. The treatment of metastasis is still not satisfactory, mainly due to lack of effective drugs [3]. Therefore, it is necessary to find new effective drugs to fight against metastasis for CRC.

Thymol is an active monoterpene isolated from many medicinal herbs, such as Thymus vulgaris, Monarda punctate and Origanum vulgare spp [4]. It has been widely used for treatment inflammatory diseases, such as osteoarthritis [5] and asthma [6]. It reported that thymol has various bioactivities, such as anticancer [7], antibacterial [8] and antioxidant properties [9]. Despite thymol being known for its multifaceted activities, the anti-metastatic ability on colorectal carcinoma cells has not been studied.

The present study was designed to explore the effect of thymol on metastasis in human colorectal carcinoma cells. In view of its effects on the phosphorylation of PI3K/AKT and ERK pathways, the underlying mechanisms of how thymol inhibits cell migration and invasion, and EMT were explored.

\section{EXPERIMENTAL}

\section{Chemicals and reagents}

Thymol $\left(\mathrm{C}_{10} \mathrm{H}_{14} \mathrm{O}\right.$, MW: 150.22 , purity $\left.\geq 98 \%\right)$ was purchased from Sigma (St. Louis, USA). It was dissolved in dimethylsulfoxide (DMSO) as stock solution of $10 \mathrm{M}$, stored at $-20{ }^{\circ} \mathrm{C}$, and freshly diluted with RPMI-1640 medium (Gibco, Carlsbad, CA) to the final concentration used in the study. [3-(4, 5-dimethylthiazol-2-yl)-2, 5dipheny-tetrazoliumbromide] (MTT) was obtained from Sigma (St. Louis, USA). Antibodies against the following targets: AKT, phosphor-AKT, ERK, phosphor-ERK, and GAPDH were purchased from Bioworld Technology, Inc. (Louis Park, MN).

\section{Cell culture}

The human colorectal adenocarcinoma HT29 cell (American Type Culture Collection, Bethesda, MD, USA) were cultured in RPMI1640 medium (Gibco, Carlsbad, CA, USA) supplemented with $10 \%$ fetal bovine serum (Gibco, Carlsbad, CA, USA), $100 \mathrm{U} / \mathrm{mL}$ penicillin and $100 \mathrm{mg} / \mathrm{mL}$ streptomycin. Cells were cultured under a humidified $5 \% \mathrm{CO}_{2}$ atmosphere at $37^{\circ} \mathrm{C}$.

\section{Cell viability assay}

Cell viability was measured using the colorimetric MTT assay as described previously $[10,11]$. The cells were cultured in 96-well plates overnight and treated with thymol $(0.5,1,2,4 \mathrm{mM})$ for 24 and $48 \mathrm{~h}$. Thereafter, cell viability was determined by MTT.

\section{Cell migration assay}

A Transwell assay was employed to determine cell migration [12]. HT29 cells $\left(1 \times 10^{4}\right.$ cells/well) was added into the upper chamber of the Transwell plates, and treated with thymol $(0.5,1$ and $2 \mathrm{mM}$ ), while the lower chamber contained $600 \mu \mathrm{L}$ culture medium with $10 \%$ FBS. After treatment for $24 \mathrm{~h}$, the cells that migrated to the bottom face of the membranes were stained with crystal violet solution and further extracted with $10 \%$ acetic acid. The absorbance at $540 \mathrm{~nm}$ represents the number of cells that migrated across the membrane.

\section{Cell invasion assay}

Cell invasive activity was performed by Matrigel assay [13]. Briefly, $5 \times 10^{4}$ cells were added to the chamber, and $100 \mu \mathrm{L}$ Matrigel was added to the lower chamber. After incubation for $24 \mathrm{~h}$, the cells were fixed with $4 \%$ formaldehyde, stained with crystal violet and further extracted with $10 \%$ acetic acid. The absorbance at $540 \mathrm{~nm}$ represents the number of cells that invaded across the Matrigel.

\section{Gelatin zymography assay}

The activity of MMP-2 and -9 were analyzed by using the gelatin zymography assay [14]. The HT29 cells were incubated with thymol $(0.5,1$ and $2 \mathrm{mM}$ ) for $24 \mathrm{~h}$. The supernatants were separated by $10 \%$ SDS-PAGE containing $1 \%$ $(\mathrm{m} / \mathrm{v})$ gelatin. The gels were visualized after staining with Coomassie blue and then photographed.

\section{Western blotting}

Cell lysates from HT29 cells were extracted in NP40 lysis buffer, separated by $10 \%$ SDSPAGE gel and further transferred to PVDF membranes. The membranes were blocked with $5 \%$ nonfat milk for $2 \mathrm{~h}$, and incubated with specific primary antibodies overnight at $4{ }^{\circ} \mathrm{C}$, and then incubated with secondary antibody for $1 \mathrm{~h}$ at $37^{\circ} \mathrm{C}$. The protein bands were visualized with ECL reagent (Millipore, Billerica, MA, USA). 
Quantitative polymerase chain reaction (qPCR) assay

Total RNA from HT29 cells was extracted with TRIzol according to the kit manufacturer's instructions. RNA was transcribed to CDNA, which were analyzed for the expression of $\mathrm{E}$ cadherin, Vimentin, $\alpha$-SMA, Snail and Slug by IQ SYBRGreen Supermix (Bio-Rad, Hercules, CA, USA). Primers were obtained from Sangon Biotech (Shanghai, China) and the details of the primers were listed in Table 1.

\section{Statistical analysis}

The data are given as mean \pm SEM $(n=3)$. Differences between the groups were analyzed using SPSS software and one-way analysis of variance (ANOVA) followed by Dunnett's test. $P$ $<0.05$ was considered statistically significant.

\section{RESULTS}

\section{Effect of thymol on viability in HT29 cells}

Firstly, we investigated the effect of thymol on cell viability at different concentrations $(0.5,1,2$ and $4 \mathrm{mM}$ ). As shown in Figure 1, after treatment for 24 and $48 \mathrm{~h}$, thymol markedly (4 mM) inhibited the cell viability in HT29 cells. Therefore, further studies were conducted using thymol $(0.5,1$ and $2 \mathrm{mM})$ to avoid its cytotoxicity.

\section{Effect of thymol on cell migration}

To evaluate the anti-metastatic effect of thymol on HT29 cells, the migration of HT29 cells by Transwell assay was performed. As shown in Figure 2, thymol (1 and $2 \mathrm{mM}$ ) treatment led to an obvious decrease in HT29 cell migration across the membrane, compared to the control group.

\section{Effect of thymol on cell invasion}

HT29 cells were added into the upper chamber of Transwell insert pre-coated with Matrigel. After treatment with thymol $(0.5,1$ and $2 \mathrm{mM})$ for $24 \mathrm{~h}$, there was a concentration-dependent decrease on the invasion of HT29 cells, compared to the control (Figure 3).

\section{Effect of thymol on MMP-2 and MMP-9} activities

We evaluated the effects of thymol on extracellular matrix degradation catalyzed by MMPs with gelatin zymography assay. Figure 4 showed that thymol $(0.5,1$ and $2 \mathrm{mM})$ decreased the activity of MMP-2 and MMP-9 in a concentration-dependent manner.

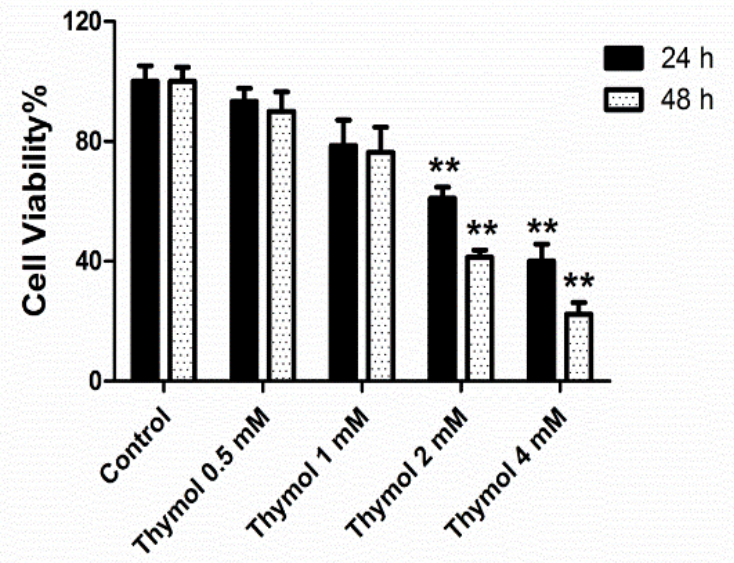

Figure 1: Effect of thymol on the cell viability in HT29 cells. HT29 cells were incubated with thymol $(0.5,1,2$, and $4 \mathrm{mM}$ ) for 24 and $48 \mathrm{~h}$, and cell viability was examined by MTT assay. Data are expressed as mean $\pm \operatorname{SEM}(\mathrm{n}=3) ;{ }^{*} p<0.05,{ }^{* *}: p<0.01$ vs control

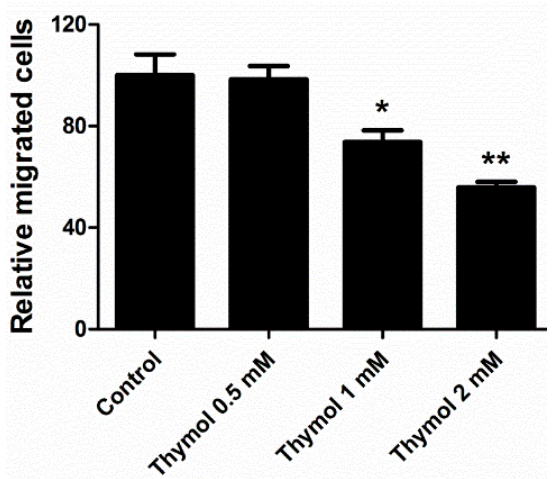

Figure 2: Effect of thymol on cell migration. HT29 cells were incubated with thymol $(0.5,1$ and $2 \mathrm{mM})$ for $24 \mathrm{~h}$, and cell migration was analyzed by Transwell assay. Migrated cells were stained with Crystal violet and the numbers of migrated cells were determined by absorbance at $540 \mathrm{~nm}$. Data are expressed as mean \pm SEM $(n=3) ;{ }^{*} p<0.05,{ }^{* *} p<0.01$ vs control real-time PCR

Table 1: Primer sequences oßraotirse used in

\begin{tabular}{ll} 
Forward primer 5'-3' & Reverse primer 5'-3' \\
\hline GAGCCTGAGTCCTGCAGTCC & GTATTGCTGCTTGGCCTCA \\
AAAGTGTGGCTGCCAAGAAC & AGCCTCAGAGAGGTCAGCAA \\
GGGTACCACCATGTACCCA & CACAGTTGTGTGCTAGAGGC \\
CCCCAATCGGAAGCCTAACT & CGTAGGGCTGCTGGAAGGTA \\
CCATTCCACGCCCAGCTA & CTCACTCGCCCCAAAGATGA
\end{tabular}




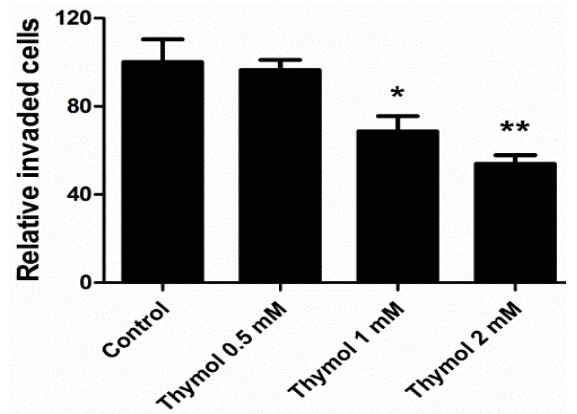

Figure 3: Effect of thymol on cell invasion. HT29 cells were treated with thymol $(0.5,1$ and $2 \mathrm{mM})$ for $24 \mathrm{~h}$, and cell invasion was detected by Transwell assay. Invaded cells were stained with Crystal violet and the numbers of invaded cells were obtained by absorbance at $540 \mathrm{~nm}$. Data are expressed as mean \pm $\operatorname{SEM}(\mathrm{n}=3) ;{ }^{*} p<0.05,{ }^{* *}: p<0.01$ vs control

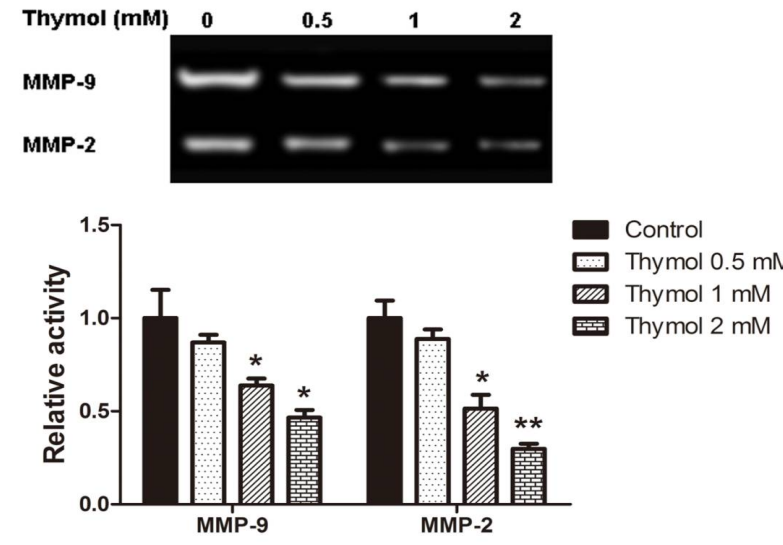

Figure 4: Effect of thymol on MMP-2 and MMP-9 activities. HT29 cells were treated with thymol $(0.5,1$ and $2 \mathrm{mM}$ ) for $24 \mathrm{~h}$. MMP-2 and MMP-9 on the degradation of gelatin were assessed. Data are expressed as mean $\pm \operatorname{SEM}(\mathrm{n}=3) ;{ }^{*} p<0.05,{ }^{* *}: p<$ 0.01 vs control

\section{Effect of thymol on epithelial-mesenchymal transition (EMT)}

Whether thymol plays important roles in EMT of colon cancer cells HT29, we analyzed the mRNA expression of major EMT biomarkers, including E-cadherin, Vimentin, a-SMA, Snail and Slug by using real-time PCR. As shown in Figure 5, thymol (2 mM) markedly increased the mRNA expression of E-cadherin, while decreased the mRNA expression of $\alpha-S M A$, Vimentin, Snail and Slug.

\section{Effect of thymol on the PI3K/AKT and ERK pathway}

To find out whether the effect of thymol on HT-29 cell invasion and migration involves PI3K/AKT or MAPK/ERK pathway, Western blot was performed to evaluate the protein levels of certain markers, including $\mathrm{p}-\mathrm{AKT}$ and $\mathrm{p}$-ERK. The results showed that thymol markedly decreased the phosphorylation levels of AKT and ERK, while it had no significant effect on the total levels of AKT and ERK in a concentrationdependent manner (Figure 6).

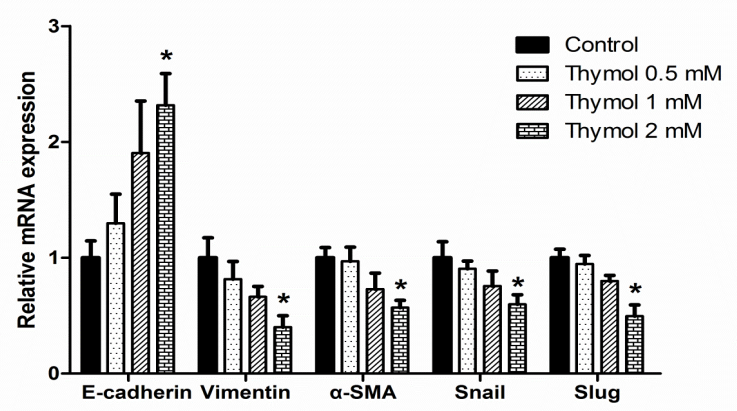

Figure 5: Effect of thymol on the mRNA expression of EMT-associated genes. HT29 cells were treated with thymol $(0.5,1$ and $2 \mathrm{mM})$ for $24 \mathrm{~h}$. Total RNA were extracted and the mRNA expression of E-cadherin, Vimentin, $\alpha-S M A$, Snail and Slug were measured by real-time PCR assay. Gene expressions were normalized to $\beta$-actin. Data were expressed as means \pm SEM of three independent experiments *: $P<0.05$, ${ }^{* *}: \mathrm{P}<0.01$ vs control

\section{DISCUSSION}

Metastasis is one of the major reasons of high mortality in CRC patients [15]. EMT, a process that tumor cell migrated and invaded from the surrounding tissue to the circulation, is characterized as the early step of the metastatic process [16]. Therefore, a compound that can effectively restrain cancer cell migration and invasion has the potential to be developed as a candidate drug for preventing or treating metastatic cancers. In this study, thymol significantly inhibited the migration and invasion in HT29 cells. It decreased the activity of MMP-2 and MMP-9. The mechanisms may involve the inhibition of EMT and downregulation of the activation of PI3K/AKT and ERK signaling pathways.

Invasion and migration have been acknowledged as the most lethal attributes of solid tumors and account for the majority of metastases [17]. Tumor cells have the ability to migrate from the original site to the blood and lymph, and invade surrounding or distant tissues, causing metastasis. Our results from the present study showed that thymol could suppress migration and invasion in HT29 cells.

MMPs, a group of zinc-dependent endopeptidases, are important mediators of invasion and degradation of basement membranes and extracellular matrix [18]. MMP-2 
A

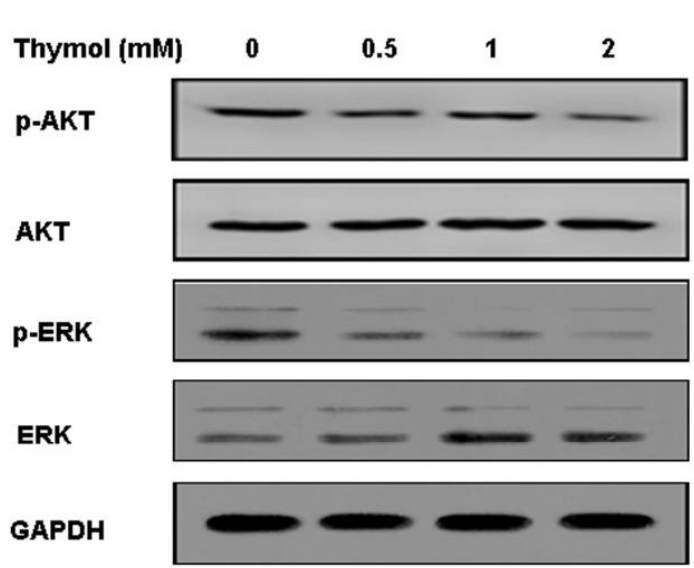

B
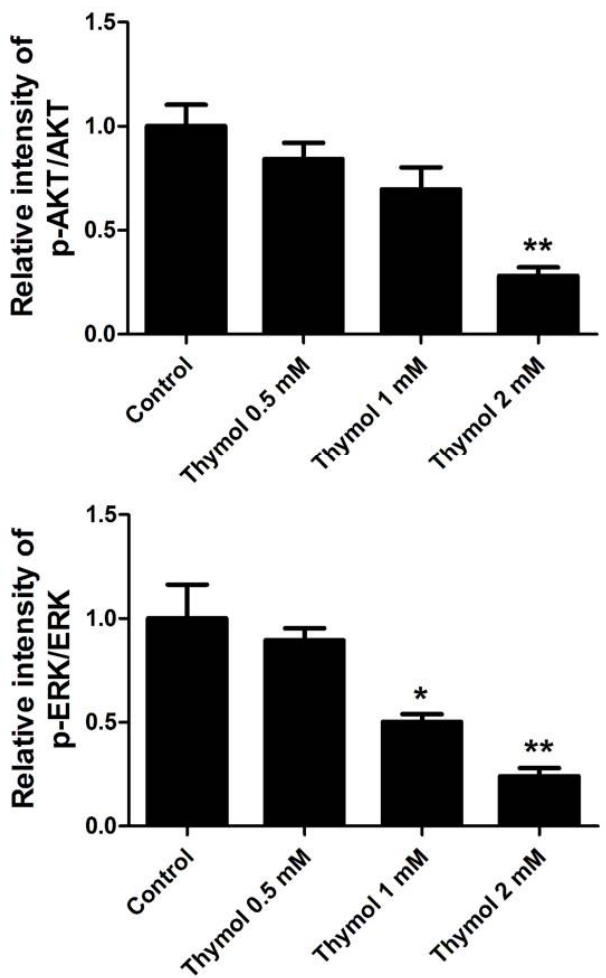

Figure 6: Effect of thymol on the activation of PI3K/AKT and ERK pathways. HT29 cells were treated with thymol $(0.5,1$ and $2 \mathrm{mM})$ for $24 \mathrm{~h}$. (A) Cells were harvested and lysed, and the levels of p-AKT, AKT, p-ERK, ERK and GAPDH were assessed by Western blot. (B) Densitometry analysis of immunoblotting was also shown. Data were presented as means \pm SEM of three independent experiments ${ }^{*}: \mathrm{P}<0.05,{ }^{* *}$ : $\mathrm{P}<0.01$ vs control

and MMP-9 abundantly expressed in various cancers, are considered to play key roles in tumor invasion and metastasis [19]. In addition, mounting evidence suggests that inhibition of MMP-9 and MMP-2 by chemopreventive agents suppresses the invasiveness and metastases of many cancer cells $[20,21]$. In the present study, thymol (1 and $2 \mathrm{mM}$ ) markedly reduced the activity of MMP-2 and MMP-9 in HT29 cells.

Numerous studies have reported the correlation between EMT and cancer progression and metastasis [22]. Epithelial-derived tumor cells become malignant and obtain an invasive phenotype is mainly through an EMT process [23]. Several molecular markers, the downregulation of epithelial cell surface marker Ecadherin, the up-regulation of mesenchymal markers vimentin and $\alpha-S M A$, and the EMTinducing transcription factors such as Snail and Slug, are the representative phenotypes of EMT [24]. Our results revealed that thymol inhibited EMT, evidenced by increasing expression of Ecadherin, decreasing the expression of vimentin and $\alpha-S M A$, and associated transcription factors Snail and Slug.
PI3K/AKT pathway overactivation is frequently present in CRC and is associated with tumor progression processes, including cell proliferation, migration and invasion [25]. It has been shown to contribute to tumor metastasis by promoting the secretion of MMPs and the induction of EMT [26]. It reported that MAPKs, such as ERK seem to play a central role in regulating the expression of MMPs, inhibition of the MAPK pathway might also potentially prevent invasion and metastasis of a variety of tumors [27]. The Western blotting results suggested that thymol could significantly inhibit the activation of AKT and ERK in HT29 cells.

\section{CONCLUSION}

This study has demonstrated that thymol is able to inhibit the migration and invasion of HT29 human colon cancers, and reduce the activity of MMP-2 and MMP-9. The mechanisms may involve the inhibition of EMT and downregulation of the activation of PI3K/AKT and ERK signaling pathways. These results provided new insights into the anti-cancer mechanisms of thymol, which may be helpful in the development of thymol into a promising therapeutic agent against colorectal carcinoma. 


\section{DECLARATIONS}

\section{Conflicts of interest}

No conflict of interest is associated with this work.

\section{Contribution of authors}

We declare that this work was done by the authors named in this article and all liabilities pertaining to claims relating to the content of this article will be borne by the authors.

Ran LV and Zhenzhou Chen conceived and designed the study; collected and analyzed the data; and wrote the manuscript. Both authors have read the manuscript and approved for publication.

\section{REFERENCES}

1. Marmol I, Sanchez-de-Diego C, Pradilla Dieste A, Cerrada E, Rodriguez Yoldi MJ. Colorectal Carcinoma: A General Overview and Future Perspectives in Colorectal Cancer. Int J Mol Sci 2017; 18: 197.

2. Peeters $M$, Oliner KS, Price TJ, Cervantes A, Sobrero AF, Ducreux M, Hotko $Y$, Andre T, Chan E, Lordick F, et al. Analysis of KRAS/NRAS Mutations in a Phase III Study of Panitumumab with FOLFIRI Compared with FOLFIRI Alone as Second-line Treatment for Metastatic Colorectal Cancer. Clin Cancer Res 2015; 21: 5469 5479.

3. $Х u Y, X u G$, Liu $L, X u D$, Liu J. Anti-invasion effect of rosmarinic acid via the extracellular signal-regulated kinase and oxidation-reduction pathway in Ls174-T cells. J Cell Biochem 2010; 111: 370-379.

4. Saravanan S, Pari L. Protective effect of thymol on high fat diet induced diabetic nephropathy in C57BL/6J mice. Chem Biol Interact 2016; 245: 1-11.

5. Patil D, Dhaneshwar $S$, Kadam P. Diacerein-thymol prodrug: in vivo release and pharmacological screening in experimental models of osteoarthritis in Wistar rats. Inflamm Allergy Drug Targets 2015; 13: 393-405.

6. Zhou E, Fu Y, Wei Z, Yu Y, Zhang X, Yang Z. Thymol attenuates allergic airway inflammation in ovalbumin (OVA)-induced mouse asthma. Fitoterapia 2014; 96. 131-137.

7. Pathania AS, Guru SK, Verma MK, Sharma $C$, Abdullah $S T$, Malik F, Chandra $S$, Katoch $M$, Bhushan $S$. Disruption of the PIJK/AKT/mTOR signaling cascade and induction of apoptosis in HL-60 cells by an essential oil from Monarda citriodora. Food Chem Toxicol 2013; 62: 246-254.

8. Miladi $H$, Zmantar $T$, Chaabouni $Y$, Fedhila $K$, Bakhrouf A, Mahdouani K, Chaieb K. Antibacterial and efflux pump inhibitors of thymol and carvacrol against foodborne pathogens. Microb Pathog 2016; 99: 95-100.

9. Fitsiou E, Anestopoulos I, Chlichlia K, Galanis A, Kourkoutas I, Panayiotidis MI, Pappa A. Antioxidant and Antiproliferative Properties of the Essential Oils of Satureja thymbra and Satureja parnassica and their Major Constituents. Anticancer Res 2016; 36: 57575763.

10. Zhao P, Chen L, Li LH, Wei ZF, Tong B, Jia YG, Kong $L Y$, Xia YF, Dai Y. SC-III3, a novel scopoletin derivative, induces cytotoxicity in hepatocellular cancer cells through oxidative DNA damage and ataxia telangiectasia-mutated nuclear protein kinase activation. BMC Cancer 2014; 14: 987.

11. Sun $Y$, Zhao $Y$, Wang $X$, Zhao L, Li W, Ding $Y$, Kong $L$, Guo $Q$, Lu N. Wogonoside prevents colitis-associated colorectal carcinogenesis and colon cancer progression in inflammation-related microenvironment via inhibiting NF-kappaB activation through PI3K/Akt pathway. Oncotarget 2016; 7: 34300-34315.

12. Wang $Y, X u X$, Zhao $P$, Tong $B$, Wei $Z$, Dai $Y$. Escin la suppresses the metastasis of triple-negative breast cancer by inhibiting epithelial-mesenchymal transition via down-regulating LOXL2 expression. Oncotarget 2016; 7: 23684-23699.

13. Zhou $Q$, Chen J, Feng J, Xu Y, Zheng $W$, Wang J. SOSTDC1 inhibits follicular thyroid cancer cell proliferation, migration, and EMT via suppressing PI3K/Akt and MAPK/Erk signaling pathways. Mol Cell Biochem 2017.

14. Lv Q, Zhu X-Y, Xia Y-F, Dai Y, Wei Z-F. Tetrandrine inhibits migration and invasion of rheumatoid arthritis fibroblast-like synoviocytes through down-regulating the expressions of Rac1, Cdc42, and RhoA GTPases and activation of the PIJK/AKt and JNK signaling pathways. Chinese Journal of Natural Medicines 2015; 13: 831841.

15. Mlecnik B, Bindea G, Kirilovsky A, Angell HK, Obenauf $A C$, Tosolini $M$, Church SE, Maby $P$, Vasaturo $A$, Angelova $M$, et al. The tumor microenvironment and Immunoscore are critical determinants of dissemination to distant metastasis. Sci Trans/ Med 2016; 8: 327-326.

16. Lee JM, Dedhar S, Kalluri R, Thompson EW. The epithelial-mesenchymal transition: new insights in signaling, development, and disease. J Cell Biol 2006; 172: 973-981.

17. Zhao $Q$, Xu L, Sun $X$, Zhang $K$, Shen $H$, Tian $Y$, Sun $F, L i$ $Y$. MFG-E8 overexpression promotes colorectal cancer progression via AKTMMPs signalling. Tumour Biol 2017; 39: 1010428317707881.

18. Sternlicht MD, Werb Z. How matrix metalloproteinases regulate cell behavior. Annu Rev Cell Dev Biol 2001; 17: 463-516.

19. Thiyagarajan V, Lin SH, Chia YC, Weng CF. A novel inhibitor, 16-hydroxy-cleroda-3,13-dien-16,15-olide, blocks the autophosphorylation site of focal adhesion kinase (Y397) by molecular docking. Biochim Biophys Acta 2013; 1830: 4091-4101. 
20. Thiyagarajan V, Tsai MJ, Weng CF. Antroquinonol Targets FAK-Signaling Pathway Suppressed Cell Migration, Invasion, and Tumor Growth of C6 Glioma. PLoS One 2015; 10: e0141285.

21. Zhao HJ, Liu T, Mao X, Han $S X$, Liang RX, Hui LQ, Cao $C Y$, You $Y$, Zhang $L Z$. Fructus phyllanthi tannin fraction induces apoptosis and inhibits migration and invasion of human lung squamous carcinoma cells in vitro via MAPK/MMP pathways. Acta Pharmacol Sin 2015; 36: 758-768.

22. Iwatsuki M, Mimori K, Yokobori T, Ishi H, Beppu T, Nakamori S, Baba H, Mori M. Epithelial-mesenchymal transition in cancer development and its clinical significance. Cancer Sci 2010; 101: 293-299.

23. Yang J, Weinberg RA. Epithelial-mesenchymal transition: at the crossroads of development and tumor metastasis. Dev Cell 2008; 14: 818-829.
24. Ahn HM, Yoo JW, Lee S, Lee HJ, Lee HS, Lee DS. Peroxiredoxin 5 promotes the epithelial-mesenchymal transition in colon cancer. Biochem Biophys Res Commun 2017; 487: 580-586.

25. Khan MW, Keshavarzian A, Gounaris E, Melson JE, Cheon EC, Blatner NR, Chen ZE, Tsai FN, Lee G, Ryu $H$, et al. PI3K/AKT signaling is essential for communication between tissue-infiltrating mast cells, macrophages, and epithelial cells in colitis-induced cancer. Clin Cancer Res 2013; 19: 2342-2354.

26. Faes S, Dormond O. PIJK and AKT: Unfaithful Partners in Cancer. Int J Mol Sci 2015; 16: 21138-21152.

27. Yang HL, Kuo YH, Tsai CT, Huang YT, Chen SC, Chang $H W$, Lin E, Lin WH, Hseu YC. Anti-metastatic activities of Antrodia camphorata against human breast cancer cells mediated through suppression of the MAPK signaling pathway. Food Chem Toxicol 2011; 49: 290298. 